\title{
Metabolic reconstruction of sulfur assimilation in the extremophile Acidithiobacillus ferrooxidans based on genome analysis Jorge Valdés ${ }^{1}$, Felipe Veloso ${ }^{\dagger 1,3}$, Eugenia Jedlicki ${ }^{\dagger 2}$ and David Holmes ${ }^{* 1,3}$
}

Address: ${ }^{1}$ Laboratory of Bioinformatics and Genome Biology, University of Santiago (USACH), Santiago, Chile, ${ }^{2}$ Program of Cellular and Molecular Biology, I.C.B.M., Faculty of Medicine, University of Chile, Santiago, Chile and ${ }^{3}$ Millennium Institute of Fundamental and Applied Biology, Santiago, Chile

Email: Jorge Valdés - joorge77@yahoo.com.mx; Felipe Veloso - Felipe@holmeslab.usach.cl; Eugenia Jedlicki - ejedlick@med.uchile.cl; David Holmes* - dsholmes2000@yahoo.com

* Corresponding author †Equal contributors

Published: 15 December 2003

BMC Genomics 2003, 4:5I
Received: 0 I September 2003

Accepted: I5 December 2003

This article is available from: http://www.biomedcentral.com/|47|-2/64/4/5I

(c) 2003 Valdés et al; licensee BioMed Central Ltd. This is an Open Access article: verbatim copying and redistribution of this article are permitted in all media for any purpose, provided this notice is preserved along with the article's original URL.

\begin{abstract}
Background: Acidithiobacillus ferrooxidans is a gamma-proteobacterium that lives at $\mathrm{pH} 2$ and obtains energy by the oxidation of sulfur and iron. It is used in the biomining industry for the recovery of metals and is one of the causative agents of acid mine drainage. Effective tools for the study of its genetics and physiology are not in widespread use and, despite considerable effort, an understanding of its unusual physiology remains at a rudimentary level. Nearly complete genome sequences of $A$. ferrooxidans are available from two public sources and we have exploited this information to reconstruct aspects of its sulfur metabolism.

Results: Two candidate mechanisms for sulfate uptake from the environment were detected but both belong to large paralogous families of membrane transporters and their identification remains tentative. Prospective genes, pathways and regulatory mechanisms were identified that are likely to be involved in the assimilation of sulfate into cysteine and in the formation of Fe-S centers. Genes and regulatory networks were also uncovered that may link sulfur assimilation with nitrogen fixation, hydrogen utilization and sulfur reduction. Potential pathways were identified for sulfation of extracellular metabolites that may possibly be involved in cellular attachment to pyrite, sulfur and other solid substrates.

Conclusions: A bioinformatic analysis of the genome sequence of $A$. ferrooxidans has revealed candidate genes, metabolic process and control mechanisms potentially involved in aspects of sulfur metabolism. Metabolic modeling provides an important preliminary step in understanding the unusual physiology of this extremophile especially given the severe difficulties involved in its genetic manipulation and biochemical analysis.
\end{abstract}

\section{Background}

Acidithiobacillus ferrooxidans is a chemolithotrophic, mesophilic, gamma-proteobacterium that lives at $\mathrm{pH} 2$. It is found in mine drainage and coal wastes and other acidic environments and is used extensively as part of a consortium of microorganisms for the industrial recovery of met- als, such as copper and gold [1]. It can obtain all its energy and electron requirements from the oxidation of various forms of reduced sulfur and ferrous iron. It can also anaerobically reduce sulfur using electrons derived from hydrogen and it can fix nitrogen and carbon dioxide. 
The ability of A. ferrooxidans to obtain energy and electrons from sulfur and reduced sulfur compounds has been investigated at the biochemical level. [2-5]. However, less attention has been paid to the mechanisms it uses to take up sulfur (sulfate) from its environment and how it is subsequently assimilated into organic compounds such as the amino acids methionine and cysteine, iron-sulfur centers in electron transfer proteins and various sulfated metabolites [6]. A. ferrooxidans must balance its requirements for sulfate for biosynthesis with its use of sulfur as an energy and electron source. Nothing has been described regarding the regulation of these requirements. Moreover, nothing is known about the possible coordinated regulation of sulfur metabolism and hydrogen utilization and nitrogen fixation that are known from studies in other organisms to impinge upon sulfur metabolism. Furthermore, little is known for any organism about mechanisms for sulfate uptake in acid environments, especially those inhabited by $A$. ferrooxidans where high concentrations of sulfate ions and potentially competing ions such as molybdenate are frequently found. Although the internal $\mathrm{pH}$ of $\mathrm{A}$. ferrooxidans is near neutral, its periplasm and outer membrane are exposed to $\mathrm{pH} 2$ and proteins in these locations must fold and function in high concentrations of protons. Questions also arise as to how membrane transport mechanisms function in A. ferrooxidans when confronted by a $\mathrm{pH}$ gradient that covers five logs of magnitude, especially considering that in neutrophilic organisms many of these transporters are symporters or antiporters using protons to drive uptake or discharge of metabolites.

Such questions could normally be addressed by a range of genetic and biochemical experiments. Unfortunately, $A$. ferrooxidans has proved recalcitrant to standard genetic manipulation. There is only one report of transformation in A. ferrooxidans and this may be strain specific and not of general use [7] and transduction is unknown. Only recently have techniques for conjugation been established and these remain difficult to control and are of low efficiency [8]. Exacerbating the problem is the difficulty of obtaining sufficient cell mass for many biochemical assays. Given these experimental hurdles, we argue that metabolic models derived from bioinformatic analyses offer an especially attractive starting point for unraveling the interesting physiology of $A$. ferrooxidans. Such studies have already revealed valuable information regarding its amino acid biosynthesis [9], nitrogen metabolism, metal fluxes and other characteristics [10].

We have carried out a bioinformatic analysis of the genome sequence of the type strain of $A$. ferrooxidans ATCC23270 made available by The Institute for Genome Research and Integrated Genomics in an attempt to identify genes and proteins potentially involved in sulfur uptake and assimilation. Using this information, a pre- liminary model for sulfur assimilation in A. ferrooxidans is presented and possible mechanisms for its biochemical and genetic regulation are discussed. The model serves as a first attempt to understand global sulfur uptake and assimilation in A. ferrooxidans.

\section{Results and Discussion}

The results are divided into six sections for convenience of discussion. Section 1 presents the model and lists the genes that constitute the central part of the model. Section 2 describes two possible mechanism for sulfate uptake from the environment. Section 3 describes a potential pathway strongly predicted to be involved in the activation of sulfur and its incorporation into cysteine via adenosine-5'-phosphosulfate (APS). Suggestions are also made as to how this pathway might be regulated. Section 4 identifies a potential pathway for the sulfation of metabolites that might be involved in extra-cellular matrix formation via the PAPS (3'-phosphoadenosine 5'phosphosulfate) pathway. In Section 5 a proposed connection between cysteine and the formation of Fe-S centers is discussed. We also speculate about the possible role of putative regulatory genes, embedded in predicted regulons for nitrogen fixation and hydrogen oxidation, in sulfur assimilation and sulfur reduction. In Section 6 we have tried to draw together the various postulated regulatory mechanisms in order to paint a more global picture of the regulation of sulfur metabolism in A. ferrooxidans, highlighting aspects of its chemolithoautotrophic physiology.

\section{SECTION I: Proposed preliminary model for sulfur uptake and assimilation}

Figure 1 presents a preliminary model for sulfur uptake and assimilation in A. ferrooxidans derived from a bioinformatic analysis of the potential genes present in its genome. A list of the candidate genes presented in the model, their proposed functions and some of their characteristics are shown in Table 1.

\section{SECTION 2: Possible sulfate uptake mechanisms}

Microorganisms obtain sulfur either from inorganic sulfate or from organosulfur compounds such as sulfonates, sulfate esters, or sulfur-containing amino acids. Potential genes with similarity to those for the uptake of methylthioribose, arylsulfonate, sulfur ester, alkene sulfonate or taurine were not detected in the genome of A. ferrooxidans. However, candidate genes potentially encoding uptake of inorganic sulfate were discovered, including a sulfate permease belonging the SulP family of the major facilitator superfamily of transporters (MFS) and a possible sulfate/ thiosulfate/molybdenate ATP binding cassette (ABC)-type transporter.

The proposed SulP exhibits eleven predicted transmembrane helices and shows substantial conservation of 


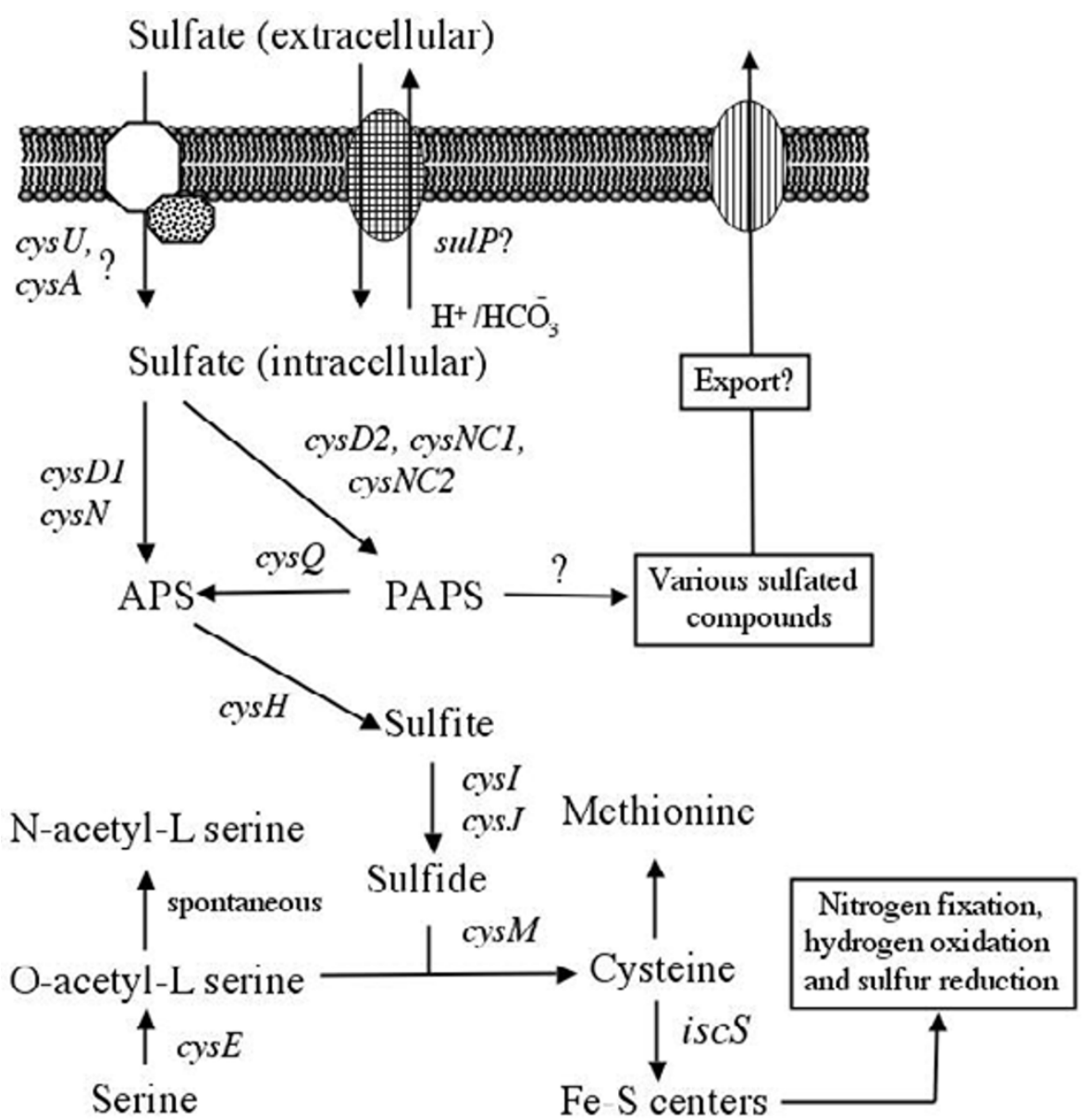

Figure I

Metabolic model for the uptake and assimilation of sulfur in A. ferrooxidans. Candidate genes are shown in italics.

amino acid sequence and predicted topology of transmembrane regions and extramembrane loops with similar proteins from a variety of neutrophilic bacteria. SulP contains the following motifs that have been identified for sulfate uptake: COG 0659, PFAM 00916 and eMOTIF IPB001902B. It also matched the sulfate uptake Tigerfam 00815, although the score was below the trusted cutoff. SulP is separated by ten base pairs from an upstream gene potentially encoding a carbonic anhydrase gene (cab1). The putative Cab1 of A. ferrooxidans exhibits the Prosite signature (PS00704) of a beta-type, prokaryotic-type carbonic anhydrase. Carbonic anhydrase catalyzes the formation of $\mathrm{HCO}_{3}$ from $\mathrm{CO}_{2}+\mathrm{H}^{+}$. Whereas SulP functions as a $\mathrm{H}^{+}$symport in most organisms [11] the juxtaposition of the putative cab1 and sulP in A. ferrooxidans in a potential transcriptional unit might facilitate the function of SulP as a $\mathrm{HCO}_{3}$ - antiporter rather than as a $\mathrm{H}^{+}$symporter. Supporting this conjecture is experimental evidence for a
SulP-like sulfate- $\mathrm{HCO}_{3}$ - antiporter in rat [12]. In addition, linkage of this gene pair is conserved in several organisms and, in the case of Leptospira interrogans, the couple appear as a gene fusion (data not shown), suggesting that the association represents a functional coupling.

An alternative hypothesis is that SulP/Cab1 can function in the reverse direction, exporting sulfate in order to import carbonate for the enhancement of $\mathrm{CO}_{2}$ fixation. Supporting this idea is the finding that carbonic anhydrase activity is associated with $\mathrm{CO}_{2}$ fixation in a number of autotrophic organisms [11].

The suggested $\mathrm{ABC}$-type membrane uptake mechanism for sulfate/thiosulfate/molybdate uptake in A. ferrooxidans consists of a membrane spanning protein (CysU), that could form a channel for sulfate, and a membrane associated ATP-binding protein (CysA) that could provide 
energy for the transmembrane transport process. CysU is predicted to contain six transmembrane regions that align with similar regions in similar proteins. The genes cys $U$ and $c y s A$ potentially form an operon-like structure (data not shown). Typically, sulfate is delivered to the ABCuptake pump by a high affinity soluble periplasmic protein [13]. Two candidate genes for this function were detected in A. ferrooxidans. One of them is embedded in a cluster of genes associated with molybdate uptake and is, therefore, more likely to be a molybdate transporter. Both candidates are members of a large paralogous gene family of $A B C$ transporters [14] and the identification of their functions awaits experimental investigation. However, bioinformatics analysis has pinpointed them as the most likely candidates for sulfate transporters thus enabling a focus for the experimental scientist.

\section{SECTION 3: Proposed pathway for sulfur assimilation into cysteine via APS \\ Activation of sulfur via APS}

After entry into the cell, sulfate is generally made biologically available by activation with ATP in a reaction catalyzed by ATP sulfurylase, yielding APS and PPi. ATP sulfurylase is a heterodimeric enzyme encoded by genes termed $c y s D$ and $c y s N$ in many organisms [15]. Potential orthologs of $c y s D$ and $c y s N$ were identified in A. ferrooxidans (Table 1). In addition, experimental evidence demonstrates that sulfate can be incorporated into APS in A. ferrooxidans [6].

\section{Reduction of APS to sulfite}

In plants, phototrophic bacteria and some other bacteria, sulfur is subsequently reduced to sulfite by APS reductase. However, in other organisms, including enteric bacteria, cyanobacteria and yeast, APS is further activated by another ATP to form PAPS that is, in turn, reduced to sulfite by PAPS reductase. APS and PAPS reductases show some $25-30 \%$ amino acid sequence identity, including a highly conserved (KRT)ECG(LS)H signature making their differentiation by bioinformatic analysis more difficult. However, it has been suggested that they can be distinguished by the presence of key motifs including two pairs of cysteine residues, characteristically found in APS reductase but not in PAPS reductase, that coordinate a $4 \mathrm{Fe}-4 \mathrm{~S}$ center $[16,17]$. A. ferrooxidans has a potential gene (termed $c y s H$ ) whose putative protein product not only exhibits the conserved (KRT)ECG(LS)H signature of the APS/PAPS reductase families but also the critical two cysteine pairs diagnostic of APS reductase (Figure 2). Therefore, we tentatively identify it as an APS reductase.

A potential gene, termed plr (PAPS-like reductase or Cys$\mathrm{H}$-like), was found in the genome of $A$. ferrooxidans whose putative protein has weak similarity with PAPS reductase. It also exhibits weak similarity $\left(\mathrm{e}^{-11}\right)$ to COG0175 (PAPS reductase) and weak similarity to Tigerfam00434 (PAPS reductase) but with a score below the trusted cutoff. An alignment of its hypothetical amino acid sequence with characterized APS and PAPS reductases reveals that it lacks the conserved signature (KRT)ECG(LS)H found in both APS and PAPS reducatses (Figure 2). However, it does have two of the four critical cysteines displayed by APS reductase (highlighted in blue and bold, Figure 2). Plr is located in a gene cluster (which will be described in section 5.3) that contains $c y s B$ and this association raises the possibility that the PAPS-like reductase may play a role in sulfur metabolism. However, at present its function remains unknown.

Af CysH
N. europeae
A. vinosum
E. coli
S. typhimurium
S. cerevisiae
Af Plr

Af CysH

N. europeae

Figure 2

Identification of a possible APS reductase in A. ferrooxidans. Alignment of two different regions of the putative APS reductase $(\mathrm{Cys} H)$ of $A$. ferrooxidans (Af) with APS and PAPS reductases from the following organisms: Nitrosomonas europaea (ZP000026I7), Allochromatium vinosum (AAF27544), E. coli KI 2 (PI7854), Salmonella typhimurium (PI7853), Saccharomyces cerevisiae (PI8408). The two APS regions are separated by the / symbol. Conserved amino acids shared by APS and PAPS reductases are shown in red. The four cysteines proposed to coordinate a $4 \mathrm{Fe}-4 \mathrm{~S}$ center in APS reductase but not PAPS reductase are identified with asterisks. The conserved APS/PAPS reductase signature (KRT)ECG(LS)H is boxed. Also aligned is part of the putative PIr (PAPS-like reductase) protein predicted from the genome of $A$. ferrooxidans in which amino acids highlighted in blue are shared with either APS or PAPS reductase and include two of the four critical cysteines of APS reductase (in bold,

blue).

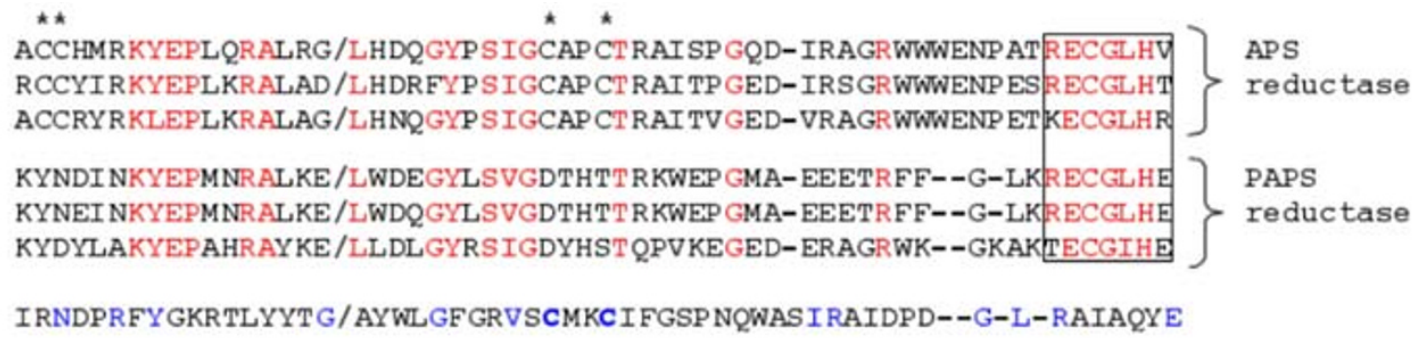




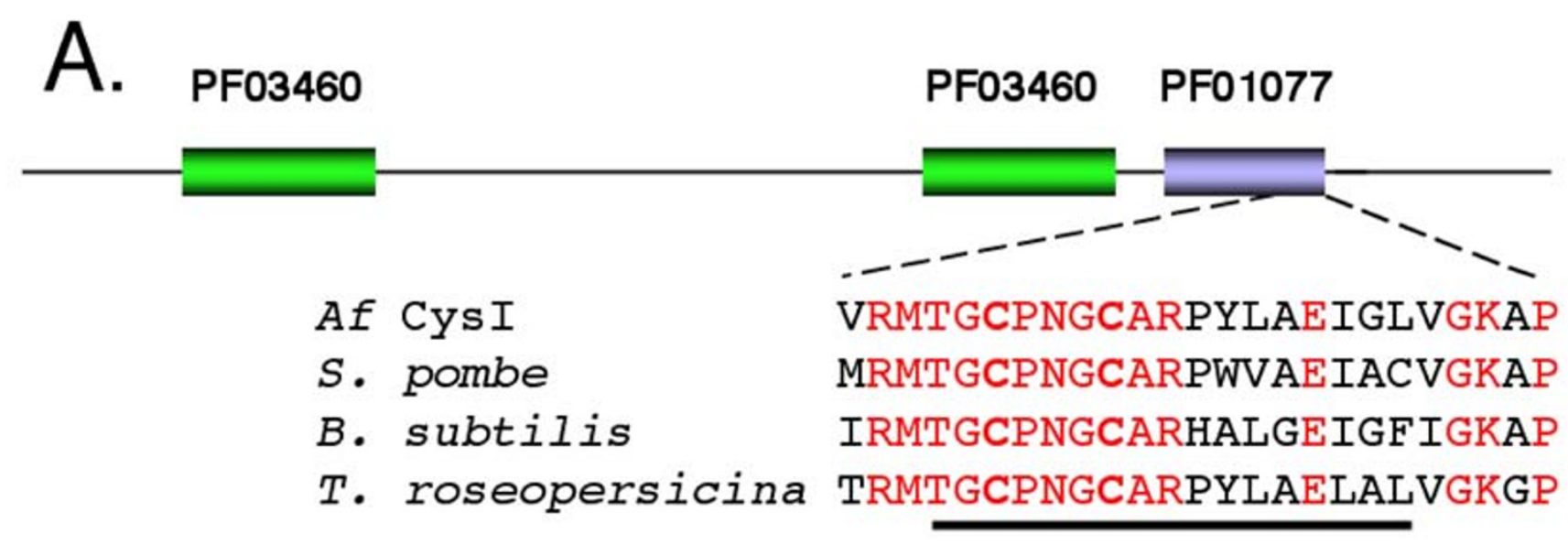

B.

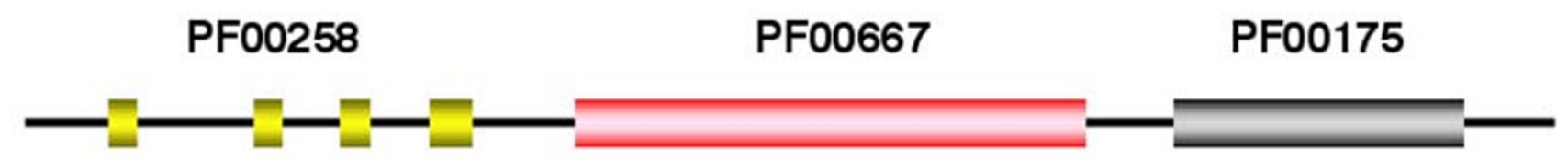

Figure 3

Domain structure of the putative Cysl and Cys] of A. ferrooxidans. (A) PFAM domain structure of the putative Cysl of A. ferrooxidans (Af). PF03460 = nitrite/sulfite reductase ferrodoxin-like half domains and PF0I077 = Nitrite and sulfite reductase 4Fe-4S binding and siroheme binding. The amino acid sequence of a conserved region at the $\mathrm{C}$-terminus of the $4 \mathrm{Fe}-4 \mathrm{~S}$ binding and siroheme binding domain is aligned with similar regions of Cysl from the following organisms: Schizosaccharomyces pombe (gi 2330803) Bacillus subtilis (gi 2635856) and Thiocapsa roseopersicina (gi I706268). The number refers to the amino acid position of the proposed Af Cysl. Conserved amino acids are shown in red. The sequence of prosite motif PS00365, [STV]-G-C-x(3)-C$x(6)-[D E]-[L I V M F]-[G A T]-L I V M F]$ is underlined. The two $C^{\prime}$ 's of this motif (shown in bold) are presumptive iron-sulfur ligands. (B) PFAM domain structure of the putative Cys] of $A$. ferrooxidans. PF00258 = flavodoxin domain, PF00667 = FAD binding domain and PFO0I75 = NAD-binding domain [19].

Reduction of sulfite to sulfide

After its formation, sulfite is typically reduced to sulfide by sulfite reductase. In bacteria, sulfite reductase is an oligomeric enzyme with a subunit composition of alpha(8)beta(4) [18]. The alpha subunit is a flavoprotein encoded by cysJ while the beta component is a siroheme, iron-sulfur protein encoded by $c y s I$. Candidate $c y s I$ and $c y s J$ were identified in A. ferrooxidans. The putative CysI exhibits the prosite motif PS00365 [STV]-G-C-x(3)-C-x(6)-[DE][LIVMF]-[GAT]-LIVMF] characteristic of the beta subunit of sulfite reductase, in which the two cysteines are involved in the coordination of the iron sulfur center (Figure 3A). CysI also contains Pfam motifs PF0340 and PF01077 characteristic of nitrite/sulfite reductase in which PF01077 contains the siroheme binding motif as well as the iron-sulfur cysteine ligands (Figure 3A). The putative CysJ contains Pfam motifs characteristic of the alpha subunit of sulfite reductase including PF00258 (flavodoxin domain), PF00175 (NAD-binding domain) and PF00667 (FAD binding domain) $[19,20]$ (Figure 3B).

A possible cys $G$ was also detected in A. ferrooxidans (Table 1 - see additional file 1) potentially encoding a uroporphyrin-III C-methyltransferase that has been shown in other organisms to be involved in siroheme formation and is, therefore, involved in the formation of CysJ. In addition to its bioinformatic identification, there is experimental evidence for the presence of a gene encoding this activity in A. ferrooxidans [21].

Formation of cysteine from $\mathrm{O}$-acetyl-L-serine and sulfide

The final step of sulfur assimilation into cysteine is the synthesis of L-cysteine from O-acetyl-L-serine and sulfide catalyzed by O-acetyl-L-serine (thiol)-lyase encoded by $c y s M$ in E. coli [18]. A cysM candidate gene was identified in A. ferrooxidans (Table 1 - see additional file 1). In most 


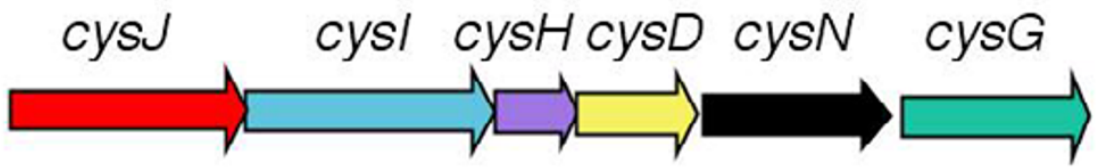

\section{Buchnera aphidicola}

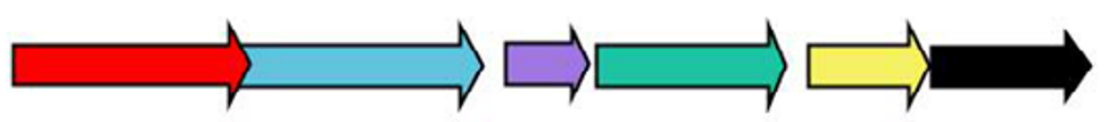

\section{Burkholderia fungorum}

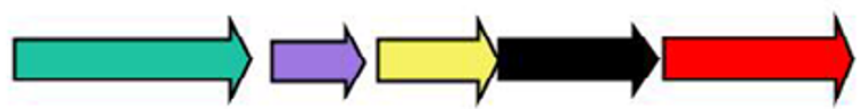

Neisseria meningitidis

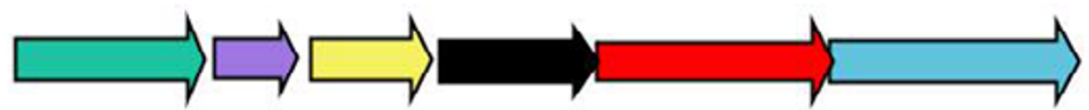

\section{Figure 4}

Organization of the proposed cys operon of A. ferrooxidans. Comparison of the organization of candidate A. ferrooxidans genes (cys operon), proposed to be involved in the assimilation of sulfur into sulfide via APS, with the genomic organization of orthologous genes from several other organisms.

organisms $\mathrm{O}$-acetyl-L-serine is synthesized from serine by the activity of serine acetyltransferase encoded by cysE. Two potential $c y s E$ genes, $c y s E 1$ and $c y s E 2$, were detected in A. ferrooxidans embedded in gene clusters predicted to be involved in the formation of $\mathrm{Fe}-\mathrm{S}$ clusters and in nitrogen fixation. The possible significance of these genetic contexts with respect to the regulation of cysteine biosynthesis is discussed below.

\section{Genetic organization and regulation of the cys operon}

The proposed genes cysJIHDNG that are speculated to be involved in the assimilation of sulfur into cysteine in A. ferrooxidans were found to be arranged in an operon-like organization denominated the cys operon. The propose cys operon exhibits considerable conservation of gene content when compared to similar operons in other organisms (Figure 4). Experimental evidence from several organisms demonstrates that the transcription of the cys operon is under the control of the positive regulator CysB. CysB belongs to the LysR family of prokaryotic transcriptional regulators that share a highly conserved helix-turnhelix DNA recognition and binding domain [22]. CysB is able to autorepress its own expression [23].

Regulatory binding sites for CysB upstream of the cys operon have been identified in Salmonella typhimurium [24]. A. ferrooxidans has two candidate copies of $c y s B$ (termed $c y s B 1$ and $c y s B 2$, Table 1 [additional file 1]) that share 95\% amino acid sequence identity. They encode potential proteins that exhibit significant conservation of amino acid sequence with characterized CysB proteins and also display the helix-turn-helix and LysR substrate binding motifs characteristic of the LysR family (Figure 5). The genomic locations of the two hypothetical $c y s B$ genes will be discussed in section 5.3.

An additional facet of $c y s$ operon regulation is that transcriptional activation via CysB requires the presence of the coinducer $\mathrm{N}$-acetylserine. In E. coli and S. typhimurium it has been shown that a reduction in the availability of sulfide leads to the accumulation of O-acetyl-L-serine that spontaneously isomerizes to $\mathrm{N}$-acetyl-L-serine. This latter compound binds to CysB inducing a conformational change that permits the protein to interact with its regulatory sites, upregulating the cys operon and restoring sulfide levels $[22,25,26]$. O-acetyl-L-serine is synthesized via the acetylation of serine by the enzyme serine acetyltranferase that is the product of $c y s E$. It is speculated that the hypothetical CysE1and CysE2, previoiusly mentioned in the formation of cysteine, are also responsible for the formation of $\mathrm{N}$-acetyl-L-serine and therefore play an important role in the regulation of the cys operon.

A second mechanism regulating cys operon activity has been proposed [18]. Excess cysteine is toxic because it promotes oxidative DNA damage by promoting the Fenton 


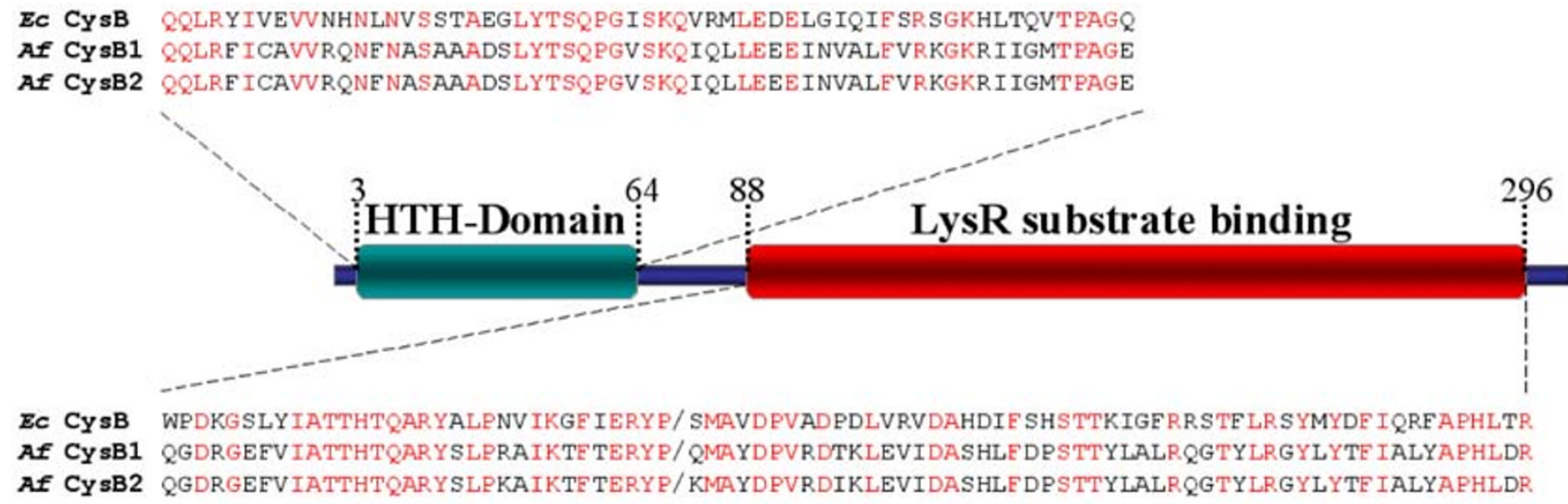

\section{Figure 5}

Comparison of the two potential CysB transcriptional regulators of $A$. ferrooxidans $(A f)$ with the well characterized $C y s B$ of $E$. coli (Ec) (gi: I583 I I0I). Conserved amino acids are shown in red. Numbers are with respect to gi: I583II0I).

reaction [27] and the synthesis of cysteine can be downregulated to prevent excess buildup via feedback inhibition on serine acetyltransferase (CysE) by cysteine. This, in turn, limits the production of O-acetyl-L-serine and, since this compound is one of the precursors of cysteine, its diminution causes a concomitant decrease in the synthesis of cysteine. A reduction of CysE activity is also predicted to reduce CysB activity that, in turn, will downregulate the expression of the cys operon.

The notable conservation of the genes and their organization in the proposed cys operon, taken together with the conservation of both the predicted CysB transcriptional activator and CysE co-activator, strongly suggests that $A$. ferrooxidans can regulate the cys operon in a manner comparable to that described for other organisms. This speculation should provoke future bioinformatic and experimental searches for CysB regulatory binding sites in appropriate regions of the A. ferrooxidans genome. Given this conservation and the fact that the $\mathrm{pH}$ of the cytoplasm of $A$. ferrooxidans is near neutral suggests that the bioinformatic predictions may be open to experimental validation by complementation of well characterized mutants in other organisms such as $E$. coli $(21,29)$.

\section{SECTION 4: Proposed sulfation of metabolites via the PAPS pathway}

Some organisms, such as enteric bacteria and fungi phosphorylate APS with a second ATP to yield PAPS using the enzyme adenylylsulfate kinase (CysC). A discrete cys $C$ was not found in the genome of $A$. ferrooxidans. However, two non-identical copies of putative genes, termed cys NC1 and $c y s \mathrm{NC2}$, were detected that appear to be fusions of $c y s \mathrm{~N}$ and $c y s C$. CysNC2 is adjacent to $c y s D 2$ that potentially encodes the small subunit of ATP sulfurylase (Figure 6). $C y s D 2$ represents a second, non-identical copy of $c y s D$, the other $(c y s D 1)$ is associated with the proposed cys operon described earlier.

The hypothetical CysNC1 and CysNC2 of A. ferrooxidans exhibit several motifs and key conserved amino acids characteristic of the fused ATP sulfurylase/kinases of other organisms (Figure 6), suggesting that they may carry out a role in PAPS biosynthesis similar to that determined in these organisms [28]. It has also been demonstrated that a segment of $A$. ferrooxidans DNA, prepared from a randomly cloned genomic library, complemented an E. coli mutant deficient in CysC activity [29] providing experimental support for the bioinformatic identification of a possible gene encoding ATP sulfurylase/kinase activity.

Fused cysN/cysC genes have been described in Rhizobium $s p$. where the fusion is termed nodQ [30]. In R. meliloti, NodP (similar to the A. ferrooxidans CysD) and NodQ (similar to the A. ferrooxidans CysNC) are required for the synthesis of PAPS which provides activated sulfur for the modification of the reducing end of Nod, a factor essential for the formation of root nodules [31]. In addition, PAPS is used in $S$. meliloti for the sulfation of cell surface polysaccharides [32]. There are two copies of nodPQ in $R$. meliloti, which are functionally redundant in the sense that both copies have to be inactivated to impair nodule formation in alfalfa [33]. PAPS also serves as a substrate in Mycobacteria for the biosynthesis of sulfolipids that may function as virulence factors [34]. In general, sulfated molecules are directed outside the cell and act as modula- 


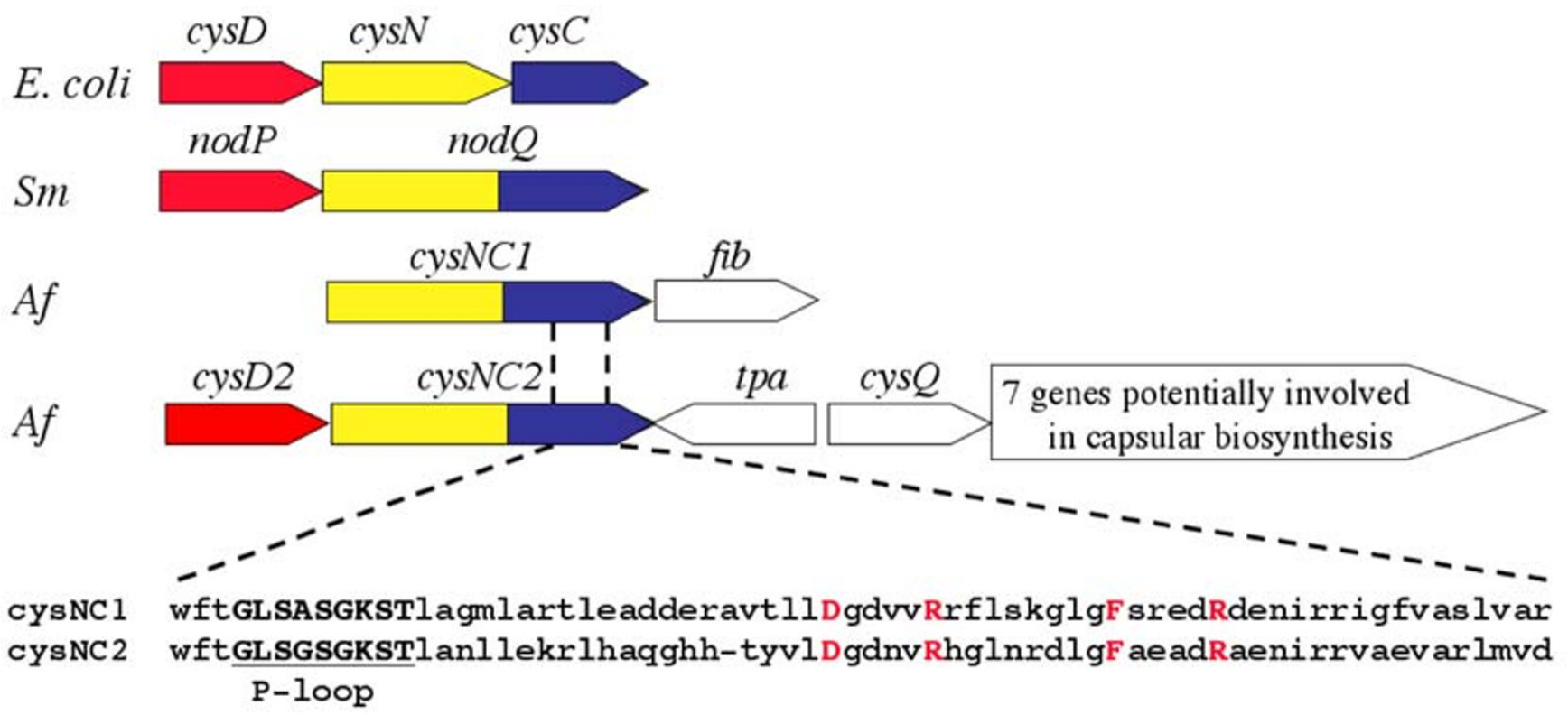

cysNC1 hggiavvaaispYrqaradarrlveeagglfievhvatpleicaeRDPKGLYAKAVRGEITGFTGVDD cysNC2 aglivlvsfispYraerefarslftpgeflevfvd--tpleecerRDPKGIYARARAGQI PNFTGISS Mobile loop

\section{Figure 6}

Organization of the proposed genes involved in PAPS formation in A. ferrooxidans. Top: Comparison of the organization of genes involved in the synthesis of PAPS in E. coli and Sinorhizobium meloti $(\mathrm{Sm})$ with the suggested organization of orthologous genes in A. ferrooxidans $(A f)$. Located downstream of cys NCI and cys NC2 inA. ferrooxidans, and potentially forming operons with these genes, are fib (weak similarity to a gene potentially encoding a fibronectin-like binding protein involved in cell adhesion), tpa (transposase), cys $Q$ (3'(2'),5'-bisphosphate nucleotidase) and an additional seven genes possibly encoding capsular biosynthesis. CysD and nodP are orthologs of cysD2. Bottom: Alignment of part of the C-terminal region of the proposed Cys $\mathrm{NCI}$ and CysNC2, corresponding to the putative kinase domain, showing conserved motifs and amino acids characteristic of this domain. Underlined and shown in bold are the P-loop and Mobile loop motifs and (in bold red) are amino acids that have been demonstrated to be critical in the kinase reaction [36]. These include the proposed MgATP-interacting Asp (D), two Phe (F) residues that straddle the adenine ring of bound APS, two $\operatorname{Arg}(R)$ residues that salt-link to the phosphosulfate group of APS, a Tyr $(Y)$ that helps align the first Arg residue and a Lys $(K)$ in an allosteric switch region.

tors of cell-cell communication and cell adhesion and PAPS serves as a universal intermediate in their biosynthesis. Given the juxtaposition of cysNC1 with a gene potentially encoding a fibronectin-like binding protein that may be involved in cell adhesion and the juxtaposition of cysNC2 with a cluster of genes potentially encoding functions involved in capsular biosynthesis (Figure 6), we speculate that $A$. ferrooxidans also utilizes PAPS as a donor for the sulfation of extra-cellular proteins which may be involved in adhesion of the organism to substrates such as sulfur and pyrite [35]. Genes potentially encoding the SecA translocase system and the PapCD chaperone-usher system were detected in the genome of $A$. ferrooxidans (data not shown), suggesting that the organism has the capacity to export and assemble adhesive structures.
An alternative, but not necessarily mutually exclusive, role for the function of the fused ATP sulfurylase/kinase protein has been suggested from studies of the kinetic constants of the A. aeolicus enzyme. This enzyme appears to be optimized, not for the formation of PAPS, but in the reverse direction generating ATP and sulfate. Consequently, in addition to its postulated role in the formation of PAPS, it may function in the opposite direction as a route to recycle PPi produced by biosynthetic reactions and for the formation of sulfate in the absence of an inorganic source of sulfate [36]. Therefore, APS appears to lie at a critical metabolic branch point [34] channeling sulfur to cysteine or to PAPS, where PAPS can serves as a substrate for sulfation of other metabolites, or, in the reverse direction for recycling PPi and sulfate. It will be important 
in the future to investigate these predictions and to determine the regulatory mechanisms that control the flux of sulfur to the two pathways.

Consistent with the contention that $A$. ferrooxidans is capable of PAPS formation is the presence of a candidate $c y s Q$, associated with the cysD2NC2 gene cluster, but separated from it by a gene potentially encoding a transposase (Figure 6). CysQ encodes a 3'(2'), $5^{\prime}$-bisphosphate nucleotidase that removes the 3'-phosphate from APS to regenerate AMP, helping to drive the APS-PAPS cycle and diminishing the toxicity of PAPS [37]. We speculate that the hypothetical CysQ performs a similar function in $A$. ferrooxidans.

The candidate CysQ of A. ferrooxidans exhibits the two prosite motifs (PDOC00547) characteristic of the enzyme as shown in the following two segments of the predicted amino acid sequence where the prosite motifs are underlined: WGFFWLVDPLDGTKEFIRKNGEYT and LGPTMEWDTAAAQIIATESGCRVEA the prosite patterns are: [FWV]-x(0,1)-[LIVM]-D-P-[LIVM]-D-[SG]-[ST]-x(2)-

[FYA]-x-[HKRNSTY] where the first D and the T bind a metal ion and [WYV]-D-x-[AC]-[GSA]-[GSAPV]-x-[LIVFACP]-[LIVM]-[LIVAC]-x(3)-[GH]-[GA], (the final [GA] is replaced by a $[\mathrm{C}]$ in the $A$. ferrooxidans sequence).

\section{SECTION 5: Formation of iron-sulfur centers and the proposed connection of sulfur metabolism with nitrogen fixation, hydrogen oxidation and sulfur reduction \\ Proposed isc operon for the formation of Fe-S centers}

Cysteine serves as the main source of sulfur for the biosynthesis of $\mathrm{Fe}-\mathrm{S}$ centers. Proteins with $\mathrm{Fe}-\mathrm{S}$ centers are key catalysts in metabolism and are central for many processes that involve electron transfer. Fe-S proteins are also involved in sensing and transcriptional control [38]. One route for $\mathrm{Fe}-\mathrm{S}$ cluster biogenesis is exemplified by a protein complex encoded by the iscSUA operon involved in the formation nitrogenase and other proteins containing Fe-S centers [39]. In this system, iscS (also known as nifS) encodes a cysteine desulfurase that removes an active sulfur from cysteine and $i c s U$ and $i s c A$ encode proteins that are thought to serve as a scaffold for Fe-S center assembly. Also, frequently forming part of the operon are $h s c A$ and $h s c B$ that encode chaperones thought to aid in Fe-S center assembly, and $f d x$ encoding a ferredoxin. The negative regulator iscR is generally found upstream of the operon. IscR has been shown to contain a $2 \mathrm{Fe}-2 \mathrm{~S}$ center that appears to be required for IscR to bind to its regulatory site and repress transcription. A model has been proposed in which IscR can sense the level of $\mathrm{Fe}-\mathrm{S}$ center formation and adjust the expression of the isc operon in accordance with requirements for $\mathrm{Fe}-\mathrm{S}$ center formation [40].
A. ferrooxidans has a putative isc gene complex that we predict is an operon and which exhibits considerable conservation of organization compared to several organisms (Figure 7). The proposed operon is also predicted to contain two genes involved in tRNA modification, one of which $(\operatorname{trm} H)$ is a predicted to encode a tRNA (Gm18) 2'O-methyltransferase activity (Tigerfam00050) [41] and the other $(\operatorname{trm} \mathrm{U})$ potentially encodes a 5-methylaminomethyl-2-thiouridylate methyl transferase that transfers a methyl-thio group from SAM to tRNA (Tigerfam00420). As well as its role in Fe-S center formation, IscS has also been shown to be involved in the addition of thionucleotides to RNA [42] which might explain the association of trm $U$ with iscS1. In addition, embedded in the proposed isc operon, is a hypothetical gene of unknown function and $c y s E 1$, one of the two copies of $c y s E$ in the genome of $A$. ferrooxidans. The possible significance of the location of cysE1 in the isc operon will be discussed in section 6 .

\section{Additional copies of iscS in a proposed nitrogen fixing regulon}

A. ferrooxidans exhibits two additional copies of the cysteine desulfurase gene iscS (termed isc2 and 3) embedded in two adjacent but divergent gene clusters that include genes predicted to be involved in nitrogen fixation (Figure 8). One of the clusters also contains $c y s E 2$, the predicted second copy of $c \gamma s E$, and additional copies of the Fe-S center biosynthesis genes iscU2 and iscA2. The gene $c y s E$ is also found embedded in the nif cluster in Synechococcus sp. and other nitrogen fixing bacteria [43].

Proposed functional relationship of cysB $\mathrm{I}$ and cysB2 with hoxA and tcrr

CysB1, encoding the positive regulator of the cys operon, was found juxtaposed to a predicted hoxA (hydrogen uptake regulator) (Figure 9). HoxA is a member of the AtoC two component response regulator family of transcriptional activators, containing CheY-like receiver, AAAtype ATPase and DNA binding domains (COG 2204.1). HoxA has significant similarity to other hoxA genes involved in the regulation of the hox regulon (hydrogen uptake and oxidation) [44]. HoxA has also been shown to be a negative regulator of its own expression [45]. Adjacent, but divergently oriented to $c y s B 1-h o x A$, is a potential twenty-one gene cluster termed the hox 1 cluster, (Figure 9A) predicted to be involved in hydrogen oxidation and hydrogenase formation, supporting the contention that hoxA regulates the expression of the hox 1 cluster. A second predicted cluster of hydrogenase expression and formation genes (hox2) that is not linked to hoxA was also detected in the genome (Figure 9A) but it is not known if this regulon could also be controlled by hoxA.

Hydrogen is an obligatory by-product of nitrogen fixation in a reaction that consumes about $27 \%$ of the electron 


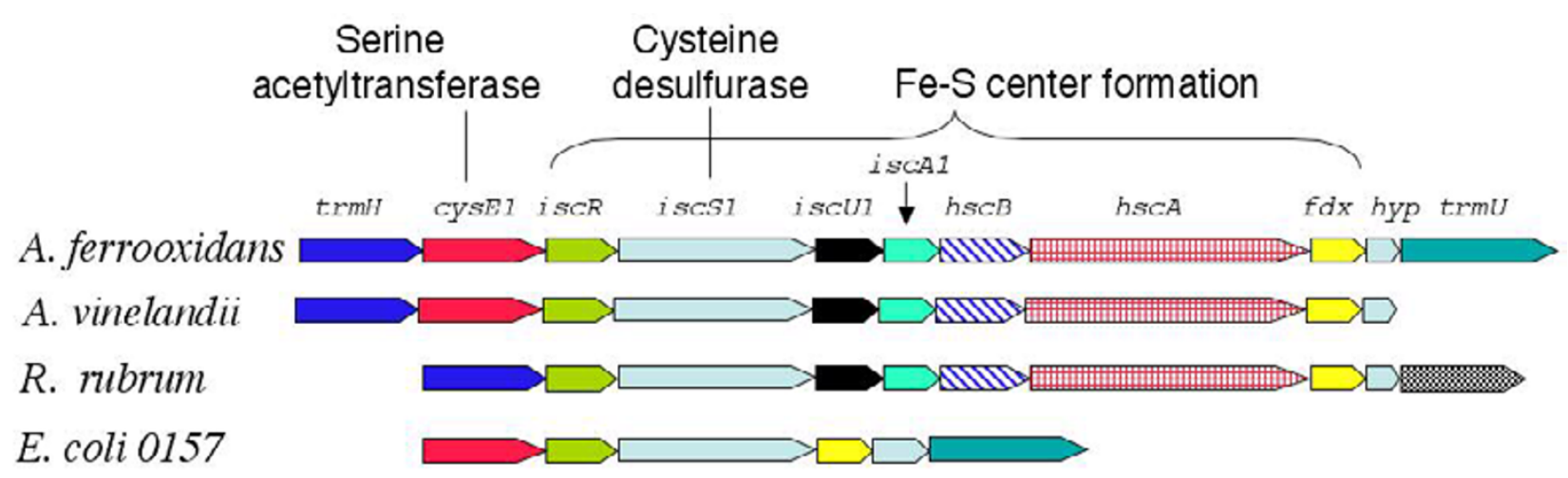

\section{Figure 7}

Proposed organization of the isc operon in A. ferrooxidans. Comparison of the putative isc gene cluster of $A$. ferrooxidans, proposed to be involved in Fe-S center formation, with similar clusters in several other organisms. The abbreviations for the genes are described in the text.

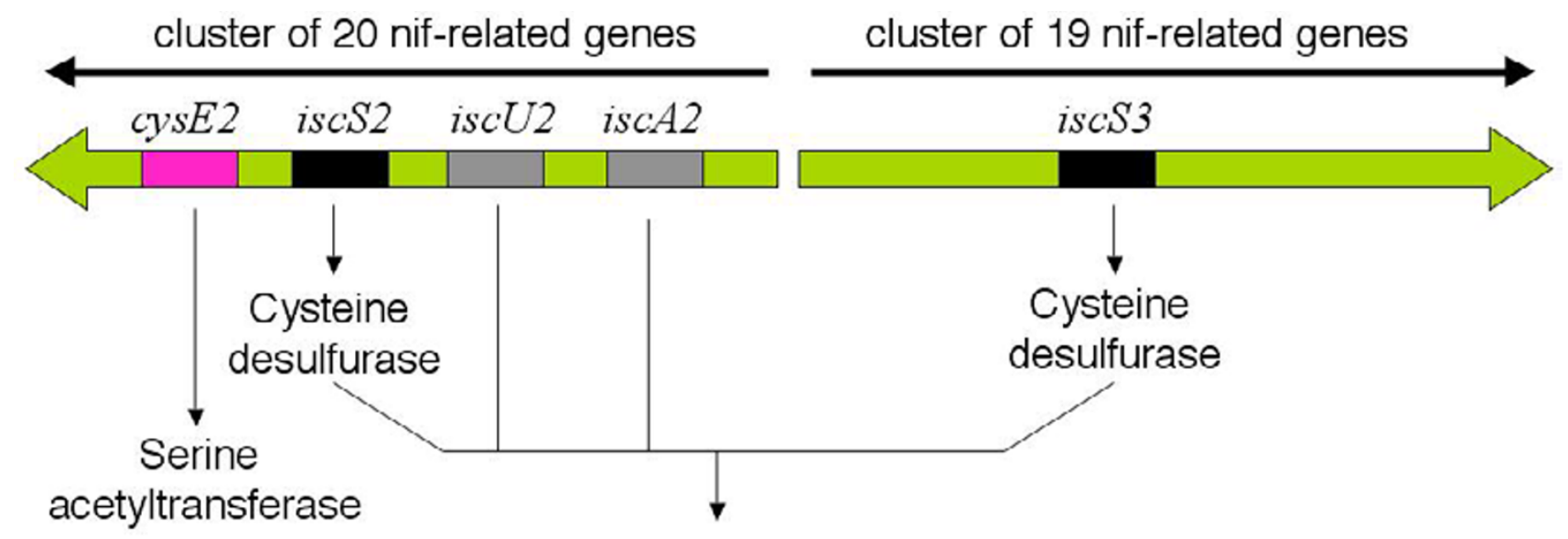

Fe-S center formation

\section{Figure 8}

Proposed locations of several potential sulfur metabolism related genes within divergent clusters of nif-related genes. The relative positions of cysE2 and members of the isc regulon and their proposed functions are shown. Potential genes predicted to be involved in nitrogen fixation form two nif-related gene clusters that are predicted to be divergently transcribed. The nifrelated genes are not shown but experimental evidence supports their functional identification [I].

flux. Some organisms export the hydrogen, while others have genes that encode hydrogen utilization functions permitting them to recover usable energy from the hydro- gen, thereby increasing their metabolic efficiency [46]. In addition, a number of organisms can oxidize hydrogen derived from the environment. Hydrogen oxidation can 

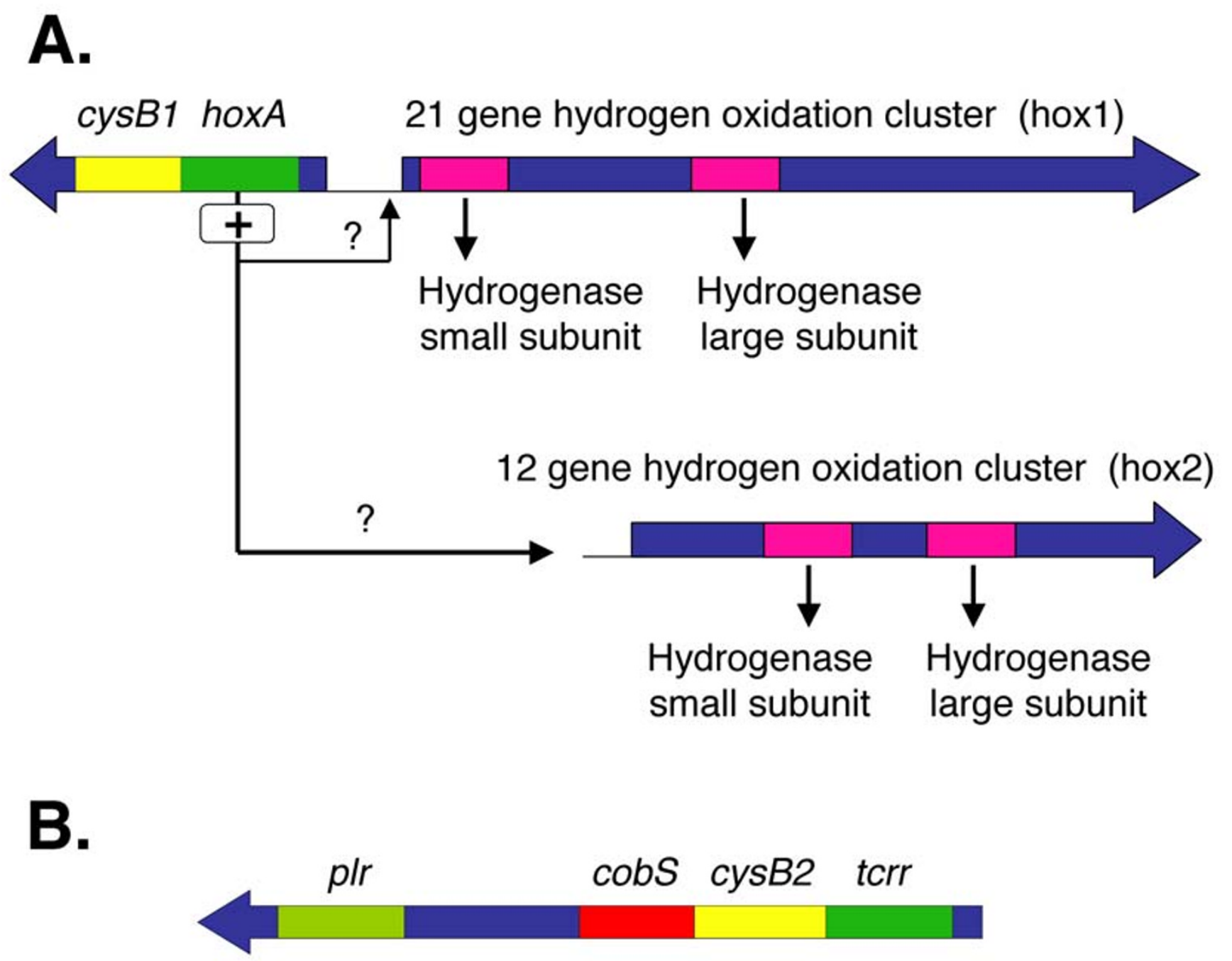

Figure 9

Predicted locations of the two candidate $c y s B$ genes in the genome of $A$. ferrooxidans. Cys $B$ is the proposed positive transcriptional regulator of the cys operon. $A$ ) $C y s B I$ is found in a possible transcriptional unit with a candidate hox $A$ that we propose could be the positive transcriptional regulator of a gene cluster (hoxl) that includes candidate genes for the hydrogenase small and large subunits and a number of auxiliary genes involved in hydrogenase formation (not shown). The cys $B / /$ hoxA gene pair is adjacent to, but transcribed in the opposite orientation, to the predicted hoxl gene cluster. There is a second potential hydrogenase formation and expression gene cluster (hox2) but it is not physically connected with the hox I gene cluster. (B) CysB2 is found in a possible transcriptional unit with a putative tcrr (transcriptional control response regulator) that has weak similarity to hoxA. Downstream, and possible in the same transcriptional unit are putative cobS and plr genes that are discussed in the text.

proceed aerobically in which electrons withdrawn from hydrogen reduce oxygen to water via a series of cytochromes resulting in the generation of a proton motif force for energy transduction. Hydrogen oxidation can also occur anaerobically in which the electrons from hydrogen are fed into the APS pathway via a protein complex encoded by the $h m c$ operon (high molecular weight cytochrome) resulting in the reduction of sulfur to sulfide [47]. The HMC complex includes a protein with an iron-sulfur center of the "bacterial-type" 4Fe-4S ferredoxins. A predicted gene cluster potentially encoding an HMC complex was detected in the A. ferrooxidans genome (data not shown) and we propose that $A$. ferrooxidans has the 
capacity to feed electrons from hydrogen oxidation into the sulfur reduction pathway.

Since A. ferrooxidans fixes nitrogen [48] it presumably generates hydrogen in the process. Various strains of $A$. ferrooxidans have also been shown to oxidize externally supplied hydrogen both aerobically and anaerobically using, in the latter case, $\mathrm{Fe}^{+3}$ or $\mathrm{S}^{0}$ as electron acceptors $[49,50]$ Unexpectedly, hydrogen did not support the growth of the strain of $A$. ferrooxidans used in the genome sequencing studies (type strain ATCC23270) [49] despite the predicted presence of the required hydrogen utilization genes. One possible explanation is that the predicted hydrogen utilization genes are used only for hydrogen oxidation during nitrogen fixation and cannot support growth using an exogenous hydrogen source. Alternatively, the right physiological conditions might not have been used in the experimental design to provoke the activity of the genes. The strong bioinformatic predictions for the presence and conservation of two potential gene clusters predicted to be involved in hydrogen utilization suggest that further experimental work is warranted to reexplore the issue of hydrogen utilization in the type strain of $A$. ferrooxidans.

The significance of the proposed transcriptional coupling between the predicted $c y s B$ and hoxA genes requires investigation. We speculate that simultaneous transcriptional activation of $c y s B$ and hoxA promotes the concomitant expression of the hox 1 regulon (and possible also the hox2 regulon) and the $c y s$ operon. Activation of the $c y s$ operon will, in turn, provide additional enzymatic activity to absorb the electron flux delivered by the oxidation of hydrogen. It will also provide increased amounts of cysteine to serve as a source of sulfur for the formation of Fe-S centers used by proteins involved in nitrogen fixation and hydrogen oxidation. In other organisms CysB and HoxA are autorepressors and their predicted juxtaposition in the A. ferrooxidans genome raises additional questions regarding their possible autoregulation and their role in global regulatory control of hydrogen utilization and sulfur metabolism.

A second copy of the cys operon regulator cysB ( $c y s B 2)$ is found adjacent to a gene termed tcrr (Fig. 9B). Tcrr exhibits the CheY-like receiver and DNA binding domains of the AtoC (COG2204.1) family of two component response regulators but it lacks the AAA-like ATPase domain characteristic of this family. It has weak similarity to HoxA (expectancy in Blast $=10^{-8}$ ) We speculate that the co-transcription of $t c r r$ and $c y s B 2$ could simultaneously activate the unknown gene targets of the tcrrA transcriptional regulator and also the cys regulon via the activity of $c y s B 2$. Tcrr is predicted to be the receiver partner of a two component transcriptional regulatory system but the activator of this partnership is not known. A consideration that may shed light on the significance of the juxtaposition of the cysB2-tcrr couple is that a potential gene, cobS, was detected that may lie within the same transcriptional unit as cysB2-tcrr (Figure 9B). CobS is predicted to be involved in cobalmin biosynthesis which is required, inter alia, for the conversion of homocysteine to methionine. This impinges on sulfur metabolism because cysteine serves as the source of sulfur for methioine biosynthesis [51]. Furthermore, downstream from cobS, but separated from it by three open reading frames whose predicted proteins have no matches in GenBank, is the putative $c y s H$-like gene plr that was described earlier. Our bioinformatic analysis underscores the need to evaluate the expression and function of plr and the predicted orphan genes since these may encode sulfur related functions peculiar to A. ferrooxidans and, therefore, merit special attention. The best hit of plr is to a phage protein (Table 1 - [see additional file 1]) suggesting that this region may have entered the A. ferrooxidans genome by lateral gene transfer.

\section{SECTION 6. Proposed integration of the regulation of sulfur assimilation with nitrogen fixation, hydrogen oxidation and sulfur reduction}

Suggestions were presented above regarding possible mechanisms for the regulation of the assimilation of sulfur into cysteine in which a proposal was made connecting the activity of $c y s B, c y s E$ and iscS to nitrogen fixation and concomitant oxidation of hydrogen and reduction of sulfur. Our metabolic reconstruction also offers an initial and preliminary view of how these components might be integrated into a regulatory network providing a first approximation of the global control of sulfur metabolism in A. ferrooxidans (Figure 10). This overview is extremely speculative, but we hope it might serve to highlight possible regulatory mechanisms worthy of experimental investigation.

At the heart of the proposed regulatory network is the pathway from sulfate to cysteine via APS, catalyzed by the cys operon $c y s J I H D N$ under the control of the positive transcriptional regulator CysB. In the event that the cell requires activation of the nitrogen fixing (nif) operon, the need for sulfur for the Fe-S centers of nitrogenase could be met by activation of the isc cluster in which iscS2 and iscS3 encoding cysteine desulfurase are embedded (Figure 8). The withdrawal of sulfur by cysteine desulfurase will lead to the depletion of cysteine. However, activation of the nif and isc operons is predicted to activate the $c \gamma s E$ genes embedded in these operons resulting in the production of $\mathrm{N}$-acetyl-L-serine that, in turn, will activate the cys operon via CysB helping to restore cysteine levels. Nitrogen fixation takes place anaerobically or microaerophilically, an 


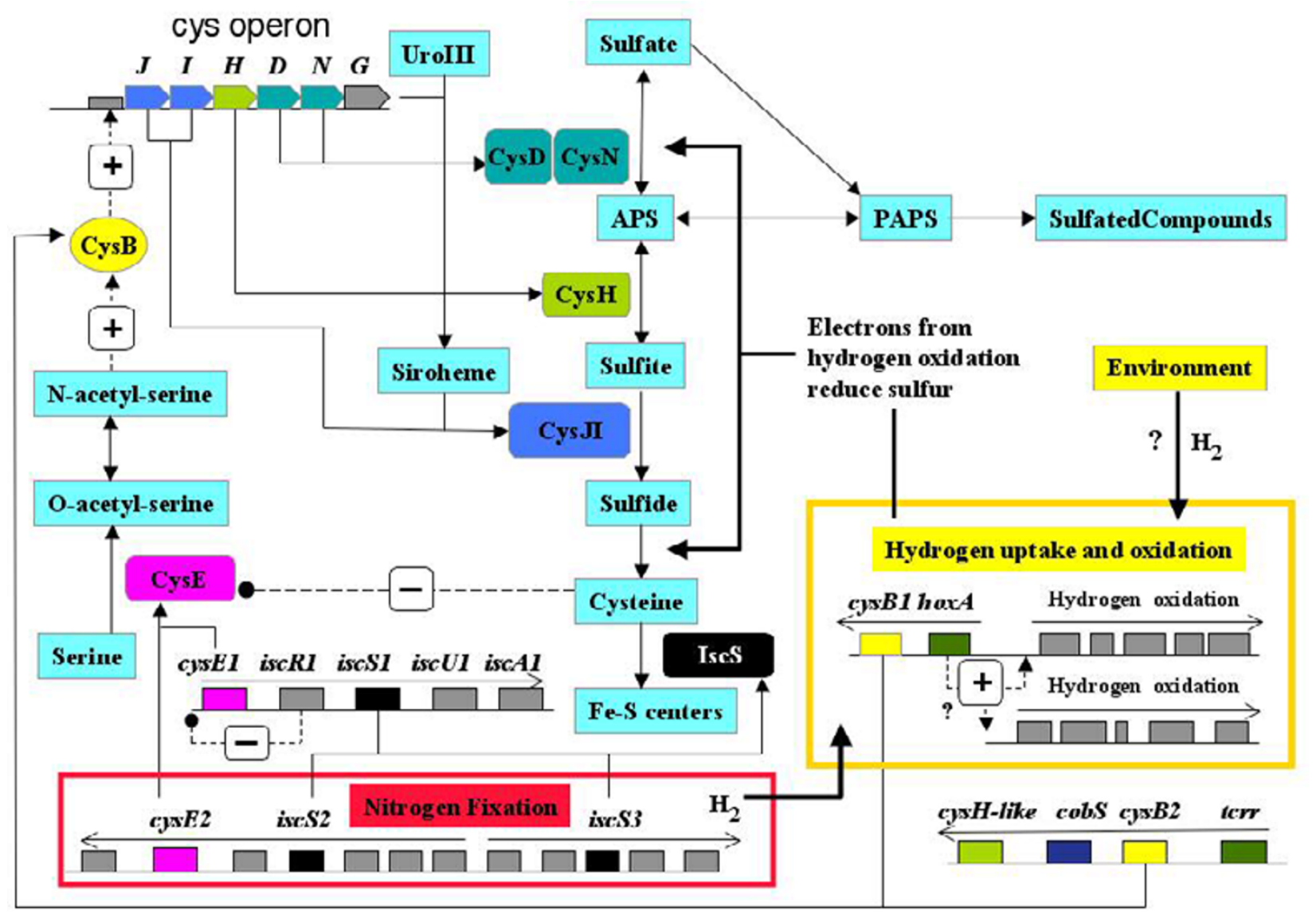

\section{Figure 10}

Preliminary model indicating aspects of the control of sulfur assimilation in A. ferrooxidans. Metabolic compounds are identified in turquoise boxes. Candidate genes and their putative protein products are coded with the same color. Genes and products suggested to be involved in nitrogen fixation and hydrogen oxidation are displayed in the red and yellow boxes respectively (not all genes have been shown for the sake of clarity). Proposed positive $(+)$ and negative $(-)$ regulatory pathways are shown with dotted lines.

important point that we will return to in the next paragraph.

The hydrogen byproduct of nitrogen fixation is predicted to activate one or both of the hydrogen regulons of A. ferrooxidans via hoxA. Hydrogen utilization requires proteins with Fe-S centers calling again for products of the isc operon. In addition, since the cell is under anaerobic conditions, the electrons from the oxidation of hydrogen will be fed into the APS pathway thereby reducing sulfate to some form of reduced sulfur, such as polysulfate, or polythionate which could be stored for later use as an energy and electron source when aerobic oxidation is restored. Electrons may also be used to reduce sulfate to sulfide. The concomitant increase of electron flux in the sulfur reduction pathway probably requires greater activity of the cys operon genes to provide the additional enzymatic activity to absorb the flux.

Associated with hoxA, the proposed transcriptional regulator of the hox1, is one of the two copies of $c y s B$. Increased CysB activity, coupled with the proposed upregulated activity of CysE, resulting from the aforementioned activation of the nif regulon, is predicted to increase levels of $c y s$ operon expression that, in turn, will help to cope with the increased electron flux from hydrogen oxidation. In addition, transcriptional activation of $\mathrm{tcrr}$ could lead to increased expression of both cobs, involved in cobalmin biosynthesis and thus methio- 
nine formation, and also of the putative gene plr with weak similarity to $c y s H$.

The presence of redundant copies of both $c y s B$ and $c y s E$ could reflect the need for alternative routes to activate the $c y s$ operon depending on different regulatory signals. This possibility merits further investigation. The model of sulfur regulation also highlights other nodes of potential regulation that deserve further exploration. For example, what are the mechanisms that dictate the flow of activated sulfur to cysteine or to sulfated metabolites at the proposed APS decision point? What regulates the expression of $c y s Q$ that is predicted to convert PAPS to APS? Absent from the model, at the present time, are the pathway connections and regulatory mechanisms that could incorporate sulfur oxidation, iron oxidation and iron homeostasis into the description of sulfur assimilation. However, their integration into the model awaits a more adequate description of these processes in A. ferrooxidans.

\section{Conclusions}

We posit that the preliminary metabolic model for sulfur uptake and assimilation in A. ferrooxidans presented here has permitted the capture of potentially biologically valid relations that have now been highlighted for experimental validation. By deconvoluting aspects of the metabolic pathway and control mechanisms involved in sulfur metabolism and how these might be integrated with other metabolic processes such as nitrogen fixation, hydrogen utilization and sulfur reduction, we hope to have provided a glimpse of the autotrophic physiology that makes A. ferrooxidans of particular interest. It is also hoped that the work of the experimental scientist has been facilitated by this study, enabling a focus on the possible and likely, pinpointing areas of particular interest and reducing the labor in search of less likely pathways and mechanisms.

The proposed metabolic model provides an important preliminary step in understanding global sulfur metabolism in A. ferrooxidans especially given the extreme difficulties involved in its genetic manipulation and biochemical analysis. It identifies some of the easier and more conspicuous aspects of the regulation of sulfur assimilation. Enfolded within the suggested model are much more complex and subtle mechanisms of regulation whose understanding will require additional bioinformatic analysis and experimental investigation.

\section{Methods}

Known metabolic pathways of sulfur assimilation were obtained from the MetaCyc database [52], KEGG [53] and ERGO [54]. Amino acid sequences derived from genes identified as being involved in sulfur assimilation were used as query sequences to search the partial genome sequence of A. ferrooxidans ATCC 23270 in the TIGR (pre- liminary sequence data was obtained from The Institute for Genomic Research through the website at http:// www.tigr.org) and ERGO [54] data bases using TblastN and BlastP [55], respectively, with default parameters. When a prospective candidate gene was identified its predicted amino acid sequence was used to formulate a BlastP search of the non-redundant data base at NCBI. Only bidirectional best hits were accepted as evidence for putative orthologs. Candidate genes and their translated proteins were further characterized employing the following bioinformatic tools available in the web: primary structure similarity relations ClustalW [56], secondary structure predictions PSI-PRED [57] and SSpred [58], transmembrane predictions TMHMM [59], motif predictions Prosite [60] and PRINTS [61], domain predictions ProDom [62], Pfam [63] and Tigrfam [64], prediction of protein localization sites Psort [65]. Information regarding the genetic organization of genes in organisms other than A. ferrooxidans were obtained from Integrated Genomics [54].

\section{Additional material}

\section{Additional File 1}

Table 1. Identification and proposed function of putative sulfur uptake and assimilation genes of $\mathrm{A}$. ferrooxidans. The best BlastP hit of each putative protein in the non-redundant GenBank is shown. $A=\%$ similarity, $B=e$ value and $C=$ score of proposed gene to its best BlastP hit and and $D=G O$ classification (Gene Ontologies, http://www.geneontol ogy.org/)

Click here for file

[http://www.biomedcentral.com/content/supplementary/14712164-4-51-S1.ppt]

\section{Acknowledgements}

Work supported by Fondecyt No. 1010623. We thank the Institute of Genome Research (TIGR) and Integrated Genomics, Inc. (IG) for the use of their partial sequence of the A. ferrooxidans genome. Sequencing of $A$. ferrooxidans was accomplished with support from the USA Dept. of Energy (DOE).

\section{References}

I. Rawlings DE: Heavy metal mining using microbes. Annu Rev Microbiol 2002, 56:65-91.

2. Rohwerder T, Sand W: The sulfane sulfur of persulfides is the actual substrate of the sulfur-oxidizing enzymes from Acidithiobacillus and Acidiphilium spp. Microbiology 2003, 149:1699-1710.

3. Ramirez P, Toledo $H$, Guiliani N, Jerez CA: An exported rhodanese-like protein is induced during growth of Acidithiobacillus ferrooxidans in metal sulfides and different sulfur compounds. Appl Environ Microbiol 2002, 68:1837-1845.

4. Masau RJ, Oh JK, Suzuki I: Mechanism of oxidation of inorganic sulfur compounds by thiosulfate-grown Thiobacillus thiooxidans. Can J Microbiol 200I, 47:348-358.

5. Sugio T, Hirose T, Ye LZ, Tano T: Purification and some properties of sulfite:ferric ion oxidoreductase from Thiobacillus ferrooxidans. J Bacteriol 1992, I74:4189-4192. 
6. Tuovinen $\mathrm{OH}$, Kelley $\mathrm{BC}$, Nicholas $\mathrm{DJ}$ : The uptake and assimilation of sulphate by Thiobacillus ferrooxidans. Arch Microbiol 1975 , I 05: I 23-127.

7. Kusano T, Sugawara K, Inoue C, Takeshima T, Numata M, Shiratori $\mathrm{T}$ : Electrotransformation of Thiobacillus ferrooxidans with plasmids containing a mer determinant. J Bacteriol 1992, 174:6617-6623.

8. Liu Z, Guiliani N, Appia-Ayme C, Borne F, Ratouchniak J, Bonnefoy V: Construction and characterization of a recA mutant of Thiobacillus ferrooxidans by marker exchange mutagenesis. J Bacteriol 2000, I 82:2269-2276.

9. Selkov E, Overbeek R, Kogan Y, Chu L, Vonstein V, Holmes D, Silver $\mathrm{S}$, Haselkorn R, Fonstein M: Functional analysis of gapped microbial genomes: amino acid metabolism of Thiobacillus ferrooxidans. Proc Natl Acad Sci USA 2000, 97:3509-35। 4

10. Barreto M, Quatrini R, Bueno S, Arraigada S, Valdes J, Silver S, Jedlicki E, Holmes DS: Aspects of the predicted physiology of Acidithiobacillus ferrooxidans deduced from an analysis of its partial genome sequence. Hydrometallurgy 2003, 71:97-105.

II. Tripp BC, Smith K, Ferry JG: Carbonic anhydrase: new insights for an ancient enzyme. J Biol Chem 200I, 52:486I5-486I8.

12. Bissig M, Hagenbuch B, Stieger B, Koller T, Meier PJ: Functional expression cloning of the canalicular sulfate transport system of rat hepatocytes. J Biol Chem 1994, 269:3017-302I.

13. Jacobson BL, He JJ, Vermersch PS, Lemon DD, Quiocho FA: Engineered interdomain disulfide in the periplasmic receptor for sulfate transport reduces flexibility. Site-directed mutagenesis and ligand-binding studies. J Biol Chem I991, 266:5220-5225

14. Holland B, Blight MA: ABC-ATPases, adaptable energy generators fuelling transmembrane movement of a variety of molecules in organisms from bacteria to humans. J Mol Biol 1999, 293:381-399.

15. Leyh TS, Taylor JC, Markham GD: The sulfate activation locus of Escherichia coli KI2: cloning, genetic, and enzymatic characterization. J Biol Chem 1988, 263:2409-24I6.

16. Berendt U, Haverkamp T, Prior A, Schwenn JD: Reaction mechanism of thioredoxin: 3'-phospho-adenylylsulfate reductase investigated by site-directed mutagenesis. Eur J Biochem 1995, 233:347-356.

17. Kopriva S, Buchert T, Fritz G, Suter M, Benda R, Schunemann V Koprivova A, Schurmann P, Trautwein AX, Kroneck PM, Brunold C The presence of an iron-sulfur cluster in adenosine 5'-phosphosulfate reductase separates organisms utilizing adenosine 5'-phosphosulfate and phosphoadenosine 5'phosphosulfate for sulfate assimilation. I Biol Chem 2002 277:2|786-2|79|

18. Kredich NM: Biosynthesis of Cysteine. In: Escherichia coli and Salmonella Volume I. 2nd edition. Edited by: Neidhardt FC. ASM Press, Washington, DC; 1996:514-527.

19. Nakayama M, Akashi T, Hase T: Plant sulfite reductase: molecular structure, catalytic function and interaction with ferredoxin. J Inorg Biochem 2000, 82:27-32.

20. Crane BR, Siegel LM, Getzoff ED: Sulfite reductase structure at I.6 Å: evolution and catalysis for reduction of inorganic anions. Science 1995, 270:59-67.

21. Sugio T, Suzuki H, Tanaka T, Matsugi S, Tanaka K, Kanao T, Tano T: A DNA region that complements on Escherichia coli cysG mutation in Thiobacillus ferrooxidans. Biosci Biotechnol Biochem 1995, 59:728-730.

22. Lochowska A, Iwanicka-Nowicka R, Plochocka D, Hryniewicz MM: Functional dissection of the LysR-type CysB transcriptional regulator. Regions important for DNA binding, inducer response, oligomerization, and positive control. J Biol Chem 200I, 276:2098-2107.

23. Ostrowski J, Kredich NM: Negative autoregulation of cysB in Salmonella typhimurium: in vitro interactions of $\mathrm{Cys} B$ protein with the cysB promoter. J Bacteriol 1991, I 73:221 2-2218.

24. Hryniewicz MM, Kredich NM: Hydroxyl radical footprints and half-site arrangements of binding sites for the CysB transcriptional activator of Salmonella typhimurium. J Bacteriol 1995 I 77:2343-2353.

25. Hryniewicz MM, Kredich NM: The cysP promoter of Salmonella typhimurium : characterization of two binding sites for CysB protein, studies of in vivo transcription initiation, and demonstration of the anti-inducer effects of thiosulfate. I Bacteriol I99|, I 73:5876-5886.
26. Monroe RS, Ostrowski J, Hryniewicz MM, Kredich NM: In vitro interactions of CysB protein with the cysK and cysJlH promoter regions of Salmonella typhimurium. J Bacteriol 1990 , I 72:6919-6929.

27. Park S, Imlay JA: High levels of intracellular cysteine promote oxidative DNA damage by driving the fenton reaction. J Bacteriol 2003, I 85: 1942-1950.

28. Schwedock JS, Liu C, Leyh TS, Long SR: Rhizobium meliloti NodP and NodQ form a multifunctional sulfate-activating complex requiring GTP for activity. J Bacteriol 1994, I 76:7055-7064.

29. Fry IJ, Garcia E: Cloning and caracterization of Thiobacillus ferrooxidans genes involved in sulfur assimilation. In Biohydrometallurgy 1989:171-185.

30. Laeremans T, Coolsaet N, Verreth C, Snoeck C, Hellings N, Vanderleyden J, Martinez-Romero E: Functional redundancy of genes for sulphate activation enzymes in Rhizobium sp. BR8I6. Microbiology 1997, I 43:3933-3942.

31. Abola AP, Willits MG, Wang RC, Long SR: Reduction of adenosine-5'-phosphosulfate instead of 3'-phosphoadenosine-5' phosphosulfate in cysteine biosynthesis by Rhizobium meliloti and other members of the family Rhizobiaceae. J Bacteriol 1999, I 81:5280-5287.

32. Keating $\mathrm{DH}$, Willits MG, Long SR: A Sinorhizobium meliloti lipopolysaccharide mutant altered in cell surface sulfation. $J$ Bacteriol 2002, I 84:668|-6689.

33. Schwedock JS, Long SR: Rhizobium meliloti genes involved in sulfate activation: the two copies of nodPQ and a new locus, saa. Genetics 1992, I 32:899-909.

34. Williams SJ, Senaratne RH, Mougous JD, Riley LW, Bertozzi CR: 5'adenosinephosphosulfate lies at a metabolic branch point in mycobacteria. J Biol Chem 2002, 277:32606-32 I5

35. Gehrke T, Hallmann R, Kinzler K, Sand W: The EPS of Acidithiobacillus ferrooxidans a model for structure-function relationships of attached bacteria and their physiology. Water Sci Technol 200I, 43:I59-I67.

36. Hanna E, MacRae IJ, Medina DC, Fisher AJ, Segel IH: ATP sulfurylase from the hyperthermophilic chemolithotroph Aquifex aeolicus. Arch Biochem Biophys 2002, 406:275-288.

37. Neuwald AF, Krishnan BR, Brikun I, Kulakauskas S, Suziedelis K Tomcsanyi T, Leyh TS, Berg DE: cysQ, a gene needed for cysteine synthesis in Escherichia coli K-I 2 only during aerobic growth. | Bacteriol 1992, | 74:4| 5-425.

38. Kiley PJ, Beinert H: The role of Fe-S proteins in sensing and regulation in bacteria. Current Opinion Microbiol 2003, 6:181-I85

39. Yuvaniyama P, Agar JN, Cash VL, Johnson MK, Dean DR: NifSdirected assembly of a transient [2Fe-2S] cluster within the NifU protein. Proc Natl Acad Sci 2000, 97 :599-604.

40. Frazzon J, Dean DR: Feedback regulation of iron-sulfur cluster biosynthesis. Proc Nal Acad Sci 200 I, 98: |475 I - | 4753.

41. Persson BC, Jager G, Gustafsson C: The spoU gene of Escherichia coli, the fourth gene of the spoT operon, is essential for tRNA (Gm I 8) 2'-O-methyltransferase activity. Nucleic Acids Res 1997, 25:4093-4097.

42. Iciek M, Wodek L: Biosynthesis and biological properties of compounds containing highly reactive, reduced sulfane sulfur. Pol J Pharmacol 200I, 53:21 5-225.

43. Huang TC, Lin RF, Chu MK, Chen HM: Organization and expression of nitrogen-fixation genes in the aerobic nitrogen-fixing unicellular cyanobacterium Synechococcus sp. strain RF-I. Microbiology 1999, I45:743-753.

44. Van Soom C, Verreth C, MJ Vanderleyden J: Identification of a potential transcriptional regulator of hydrogenase activity in free-living Bradyrhizobium japonicum strains. Mol Gen Genet 1993, 239:235-240.

45. Durmowicz MC, Maier RJ: Roles of HoxX and HoxA inbiosynthesis of hydrogenase in Bradyrhizobium japonicum. J Bacteriol 179:3676-3682.

46. Lenz O, Bernhard M, Buhrke T, Schwartz E, Friedrich B: The hydrogen-sensing apparatus in Ralstonia eutropha. J Mol Microbio Biotechnol 2002, 4:255-262.

47. Rossi M, Pollock WB, Reij MW, Keon RG, Fu R, Voordouw G: The HMC operon of Desulfovibrio vulgaris subsp. vulgaris Hildenborough encodes a potential transmembrane redox protein complex. J Bacteriol 1993, I 75:4699-47II.

48. Mackintosh ME: Nitrogen fixation in Thiobacillus ferrooxidans. Gen Microbiol 1978, 1 05:215-218. 
49. Drobner $\mathrm{E}$, Huber $\mathrm{H}$, Stetter KO: Thiobacillus ferrooxidans, a facultative hydrogen oxidizer. Appl Environ Microbiol, 1990, 56:2922-2923.

50. Ohmura N, Sasaki K, Matsumoto N, Saiki H: Anaerobic respiration using $\mathrm{Fe}(3+), S(0)$, and $H(2)$ in the chemolithoautotrophic bacterium Acidithiobacillus ferrooxidans. J Bacteriol 2002, I 84:208|-2087.

5I. Roth JR, Lawrence JG, Bobik TA: Cobalmin (Coenzyme B I 2): Synthesis and Biological Significance. Annu Rev Microbiol 1996, 50:|37-|8|.

52. Karp PD, Riley M, Paley SM, Pellegrini-Toole A: The MetaCyc database. Nucleic Acids Res 2002, 30:59-6I.

53. Kanehisa M, Goto S, Kawashima S, Nakaya A: The KEGG databases at GenomeNet. Nucleic Acids Res 2002, 30:42-46.

54. Overbeek R, Larsen N, Walunas T, D'Souza M, Pusch G, Selkov EJr, Liolios K, Joukov V, Kaznadzey D, Anderson I, Bhattacharyya A, Burd H, Gardner W, Hanke P, Kapatral V, Mikhailova N, Vasieva O, Osterman A, Vonstein V, Fonstein M, Ivanova N, Kyrpides N: The ERGO genome analysis and discovery system. Nucleic Acids Res 2003, 31:164-17|.

55. Altschul SF, Madden TL, Scha!er AA, Zhang J, Zheng Z, Miller W, Lipman DJ: Gapped BLAST and PSIBLAST - A new generation of protein database search programs. Nucleic Acids Res 1997 25:3389-3402

56. Higgins D, Thompson J, Gibson T, Thompson JD, Higgins DG, Gibson T]: CLUSTAL W: improving the sensitivity of progressive multiple sequence alignment through sequence weighting, position-specific gap penalties and weight matrix choice. Nucleic Acids Res 1994, 22:4673-4680.

57. Jones DT: Protein secondary structure prediction based on position-specific scoring matrices. J Mol Biol I999, 292: 195-202.

58. Pollastri G, Przybylski D, Rost B, Baldi P: Improving the prediction of protein secondary structure in three and eight classes using recurrent neural networks and profiles. Proteins 2002 , 47:228-235

59. Krogh A, Larsson B, vonHeijne G, Sonnhammer ELL: Predicting transmembrane protein topology with a hidden Markov model: Application to complete genomes. J Mol Biol 200I, 305:567-580.

60. Hofmann K, Bucher P, Falquet L, Bairoch A: The PROSITE database, its status in 1999. Nucleic Acids Res 1999, 27:215-219.

61. Attwood TK, Beck ME, Bleasby AJ, Parry-Smith DJ: PRINTS - A database of protein motif fingerprints. Nucleic Acids Res 1994, 22:3590-3596.

62. Servant F, Bru C, Carrère S, Courcelle E, Gouzy J, Peyruc D, Kahn D: ProDom: Automated clustering of homologous domains. Briefings in Bioinformatics 2002, 3:246-25I.

63. Bateman A, Birney E, Cerruti L, Durbin R, Etwiller L, Eddy SR, Griffiths-Jones S, Howe KL, Marshall M, Sonnhammer EL: The Pfam protein families database. Nucleic Acids Res 2002, 30:276-280.

64. Haft DH, Selengut JD, White O: The TIGRFAMs database of protein families. Nucleic Acids Res 2003, 3 1:371-373.

65. Nakai K, Horton P: PSORT: a program for detecting sorting signals in proteins and predicting their subcellular localization. Trends Biochem Sci 1999, 24:34-36.
Publish with Bio Med Central and every scientist can read your work free of charge

"BioMed Central will be the most significant development for disseminating the results of biomedical research in our lifetime. "

Sir Paul Nurse, Cancer Research UK

Your research papers will be:

- available free of charge to the entire biomedical community

- peer reviewed and published immediately upon acceptance

- cited in PubMed and archived on PubMed Central

- yours - you keep the copyright
BioMedcentral 